\title{
Las ciudades del cobre. Del campamento de montaña al hotel minero como variaciones de la company town ${ }^{\star *}$
}

\begin{abstract}
This paper analyses the copper mining ex-novo settlements in Chile, built during the $X X$ century by international enterprises. As a complement to the rural territory and the traditional cities, they attend productive functions, residence necessities and other facilities, with the purpose to obtain efficient production. The paper presents four cases that belongs to the Corporación del Cobre (CODELCO), the State enterprise organized in 1971, and other two cases related to the private enterprises. They show the evolution of the settlements, from the mining town to the mining hotel, based on productive criteria that include territorial, urban and architectural operations.
\end{abstract}

Keywords: copper mining settlements in Chile, company towns, industrial architecture.

\section{Resumen}

Este artículo analiza las "ciudades del cobre" en Chile, asentamientos ex-novo construidos a lo largo del siglo XX por empresas internacionales. De manera complementaria a los territorios rurales y las ciudades tradicionales, fueron diseñadas para atender funciones productivas, residenciales y de equipamiento, con el propósito de alcanzar resultados de eficiente producción. El artículo presenta cuatro casos relacionados con la Corporación del Cobre (CODELCO), entidad estatal formada en 1971, luego de la nacionalización del cobre en Chile, y otros dos casos vinculados con la minería privada. Ponen de manifiesto la evolución experimentada por los asentamientos - desde la ciudad minera hasta el hotel minero- a partir de criterios productivos que incluyen operaciones territoriales, urbanas y arquitectónicas.

Palabras clave: asentamientos mineros del cobre en Chile, company towns, arquitectura industrial. 


\section{Ciudades del cobre y company town}

I desarrollo de la minería del cobre, a lo largo del siglo XX, tuvo como consecuencia la puesta en marcha de un conjunto de operaciones integradas de infraestructura que incluyó la construcción de obras industriales, edificios de equipamiento, viviendas e infraestructuras portuarias, para ocupar y explotar a lo ancho el territorio chileno -normalmente entendido a lo largo de su eje longitudinal- en función de la posición de los recursos y los lugares de embarque del producto, a menudo ubicados en sitios poco propicios al asentamiento humano.

Las ciudades del cobre son producto de la gestión de empresas internacionales que implantaron asentamientos ex-novo en territorios mineros para atender funciones productivas, residenciales y de equipamiento bajo el control exclusivo de la industria, con el propósito de alcanzar resultados de eficiente producción, a partir de una autosuficiencia que posibilitara el control del conjunto desde un sistema empresarial y jurídico. Al explotar recursos no renovables, las empresas establecieron y establecen su horizonte temporal y productivo a partir del volumen y la ley de los yacimientos y de las estrategias industriales de explotación.

Son herederas, contemporáneas y sucesoras de las company towns -desarrolladas en Europa y Estados Unidos por el capitalismo emergente- buscando máxima concentración de capital, trabajo, viviendas y equipamientos. Asumieron la función produc-

\footnotetext{
Arquitecto, Profesor Titular de la Facultad de Arquitectura, Diseño y Estudios Urbanos, Pontificia Universidad Católica de Chile. E-mail: egarcesf@puc.cl

* Este artículo está basado en la investigación FONDECYT 1990485, titulada "Los campamentos de la minería del cobre en Chile (1905-2000)", con participación de Eugenio Garcés como investigador responsable, Gustavo Munizaga, Mauricio Baros y Celia Baros como coinvestigadores y Marcelo Cooper como tesista.
}

tiva como principal programa, en localizaciones territoriales complementarias de las ciudades tradicionales y los territorios rurales. En la actualidad, el término company town se ocupa con amplitud, designando las ciudades industriales de distinto tipo que fueron surgiendo a partir de la Revolución Industrial: industrial villages, cités ouvrières, arbeiter siedlungen, colonias industriales, campamentos mineros.

Los ejemplos internacionales son muchos: en Estados Unidos, Lowell, Pullman y Tyrone; Saltaire y Bournville en Inglaterra; Zlín en la República Checa; Ias Salinas de Chaux, Le Creusot y Mulhouse en Francia; la Colonia Güell en Cataluña (España), entre otros. Entre los casos chilenos se encuentran Lota -relacionado con la minería del carbón; las oficinas salitreras Humberstone y Santa Laura, cerca de lquique, y Chacabuco, María Elena y Pedro de Valdivia, en la región de Antofagasta (Garcés, 1999); y el campamento Cerro Sombrero, vinculado con la explotación del petróleo, en Tierra del Fuego, entre otros.

Dal Co (1975) define a la company town como "un ideal que explicita la transformación de la base económica de la nación americana y un modelo que interpreta el mito del primer capitalismo al de una sociedad 'perfecta' al servicio de la manufactura [...] Como modelo urbanístico representa una alternativa completa a la ciudad histórica, no tanto a causa de las formas en las que se estructura, cuanto por el hecho de asumir una única y nueva función, la fábrica, sin otros fines que los de máxima eficiencia productiva, creando un sistema monocultural sin rupturas socioeconómicas".

Las company towns se instalan en la historia del urbanismo como una manufactura urbana organizada por un proyecto de ingeniería y arquitectura que formaliza y distribuye las edificaciones del área industrial, los equipamientos y la residencia, en un conjunto que alcanza una organización física, productiva y social. El modelo es adecuado a una función productiva principal como es la explota- 
Figura 1. Pullman: planta (Reps, 1965).

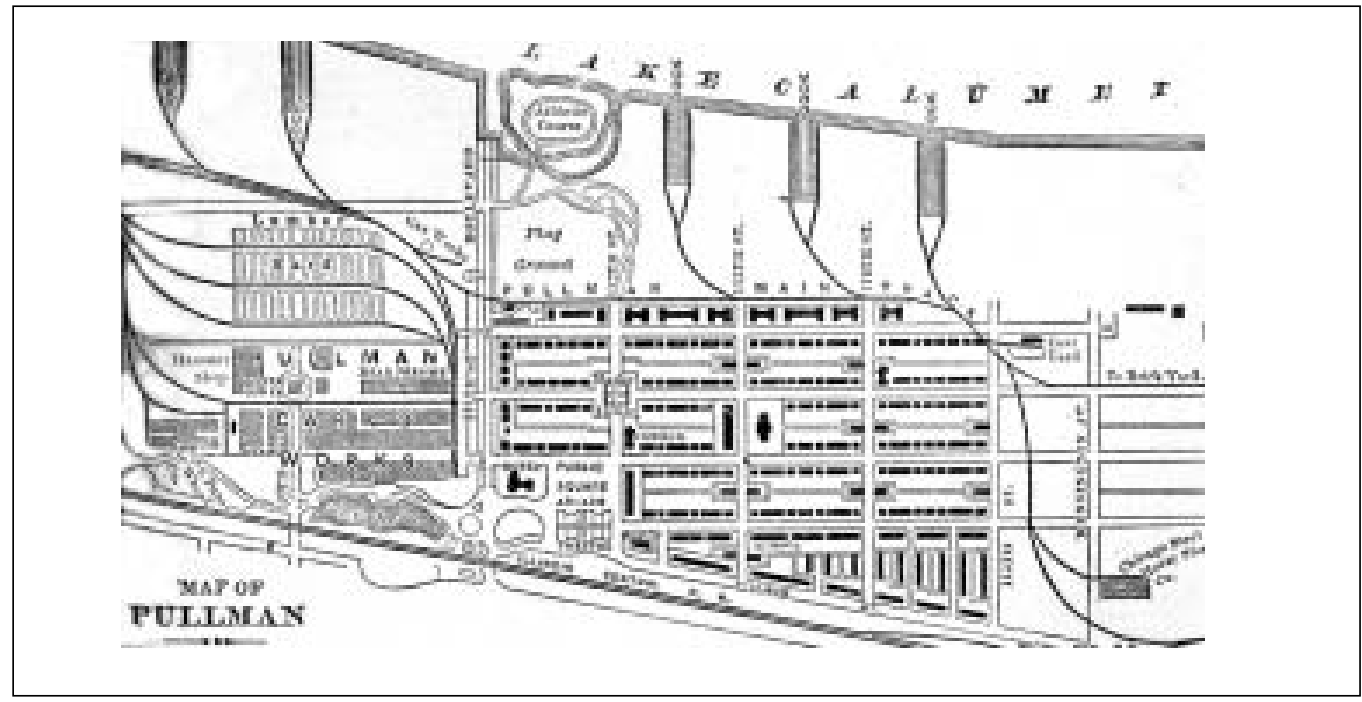

Figura 2. Chacabuco: planta (Garcés, 1999).

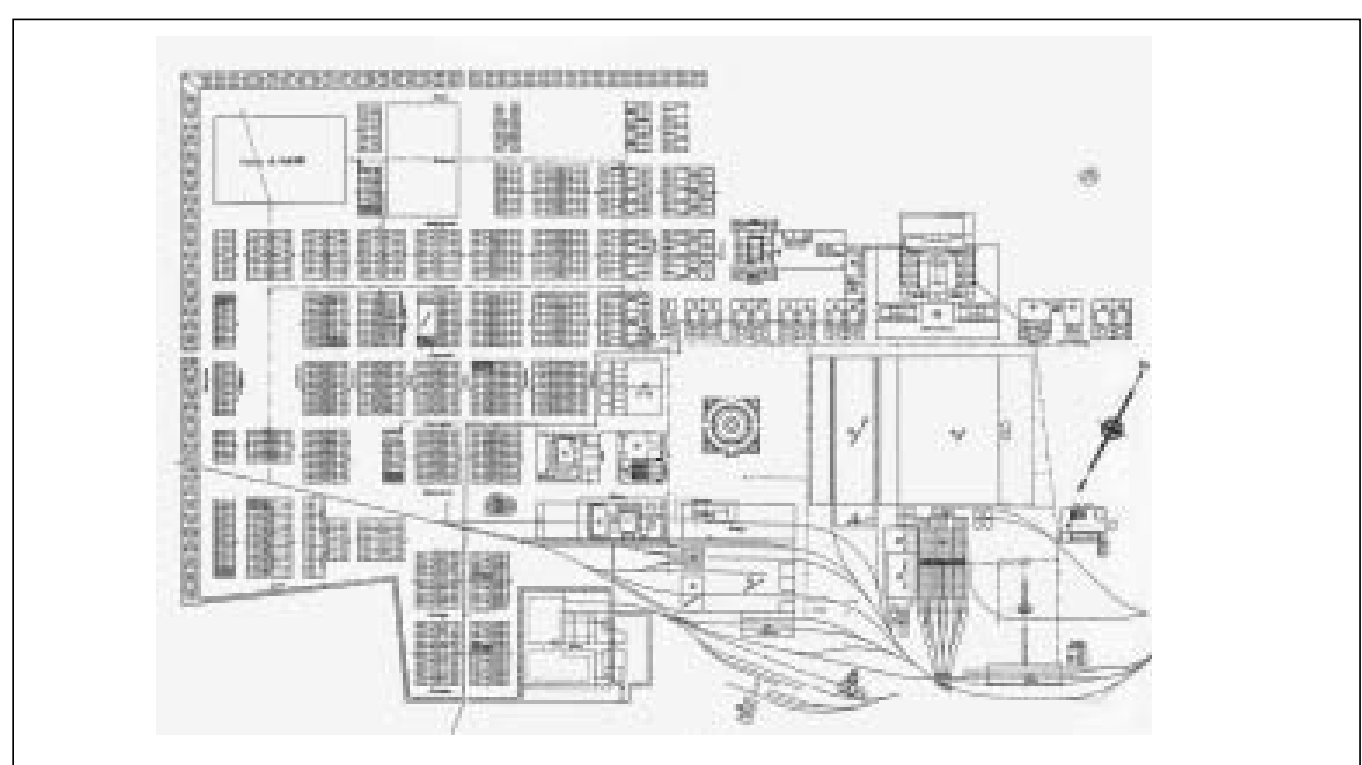

ción de materias primas y la manufactura industrial, al mismo tiempo que funcional a la modelación de un grupo social excluido de otras actividades y manifestaciones urbanas que aquellas que le entrega la compañía.

La fundación de company towns en Estados Unidos se complementa con las propuestas utópicas, destacándose aquellas paradigmáticas por su aporte teórico y proyectual, como lo son el Falansterio de Fourier, la Colonia Hogar Autosuficiente de Owen y la propuesta de Victoria de Buckingham -por citar algunos casos de los llamados socialistas utópicos. A ello hay que agregar, como un contrapunto, los medios técnicos y de infraestructura que desarrolló la Revolución Industrial, permitiendo por prime- 
ra vez, durante los siglos XIX y XX, la concentración de grandes centros de producción de materias primas en puntos específicos dentro del territorio.

Cada uno de los casos de las ciudades del cobre en Chile responde a una organización urbana y productiva que ha oscilado entre una condición arquetípica y su adecuación a determinadas preexistencias topográficas, ambientales y funcionales. Las empresas mineras han demostrando una particular flexibilidad para adaptarse a las circunstancias, de manera que las formas de los asentamientos, los tipos, materialidad, cantidad y calidad de las viviendas y de los equipamientos han ido evolucionando con nuevas tipologías, mejores estándares y avanzadas técnicas constructivas, las que con el tiempo fueron adoptándose en las ciudades tradicionales.

La concepción tradicional de campamento minero dotado de viviendas y servicios para los trabajadores y sus grupos familiares ha sido sometida a una fuerte discusión, al llevarse a cabo procesos de traslado de los habitantes a ciudades mayores de las regiones en que operaron, con el consecuente abandono y desmantelamiento del campamento original, dejando en funciones las plantas industriales. Este es el caso del Proyecto Traslado del campamento de Chuquicamata a la ciudad de Calama, distante $16 \mathrm{~km}$. De este modo, El Salvador pasaría a ser la última ciudad del cobre tradicional en operaciones, así como María Elena es la última ciudad del salitre.

Desde el punto de vista del proyecto, Sewell (1906), campamento de montaña pionero en Chile, evolucionó por prueba y error desde un campamento inicial muy precario hasta un gran asentamiento industrial de montaña, complejo en edificaciones y actividades y basado en un trazado en espina de pescado, cuyo eje es una escalera central, con derivaciones peatonales hacia una y otra ladera del Cerro Negro. Estuvo poblado por cerca de 15.000 habitantes y fue desmantelado parcialmente a partir de la llamada Operación Valle.
Chuquicamata (1915) fue desarrollado a partir de un campamento obrero de gran claridad formal, lo que permitió la agregación de conjuntos complejos de unidades de viviendas y equipamientos dotados de cierta autonomía respecto del total y muy próximos de las faenas industriales. En su momento de mayor auge estuvo habitado por cerca de 25.000 personas y actualmente (2003) se encuentra en pleno proceso de desmantelamiento.

Potrerillos (1920) tuvo un proyecto basado en el tridente barroco y experimentó una interesante evolución desde ese proyecto a un campamento más ajustado con las realidades topográficas y ambientales de la precordillera desértica de la III Región. En 1997 fue desalojado como consecuencia de la contaminación derivada de la planta de fundición, que continúa en actividad.

El Salvador (1959), proyecto urbano moderno (Raymond Olson, arquitecto, New York), fue planificado ex novo con precisión formal y funcional, a partir de un trazado geométrico de anillos concéntricos y un programa especificado en detalle. Con el tiempo, ha ido modificándose con la vitalidad de una ciudad convencional, debido al incremento de población y la necesaria dotación de nuevos servicios.

La experiencia acumulada por las empresas pioneras, en los asentamientos ya señalados, permitió a los nuevos emprendimientos mineros privados una nueva formulación del problema y de la tipología del asentamiento.

Minera Escondida (1990) planteó el concepto de villa minera, como es el caso de San Lorenzo (1995), conjunto de edificios agrupados en forma de manzana alineados a lo largo de un eje de equipamientos, diseñado para albergar a trabajadores sin sus familias en régimen de turnos, situado a una cierta distancia visual y funcional de las instalaciones industriales. 
Doña Inés de Collahuasi (1999) avanzó un paso más, al diseñar su campamento en el Salar de Coposa como una unidad integral y compacta; el Pabellón del Inca, hotel minero bien caracterizado formalmente, con espacios interiores acondicionados, servicios integrales y uso eficiente de las instalaciones.

\section{Aspectos urbanos de las ciudades del cobre}

\subsection{Sewell: el campamento de montaña (Braden Copper Company, 1906)}

Sewell está localizado a $90 \mathrm{~km}$. al sur de Santiago (Chile), aproximadamente en el paralelo $34^{\circ}$, al oriente de la ciudad de Rancagua y a 2.100 m.s.n.m. en la Cordillera de los Andes, VI Región. Forma actualmente parte de la División El Teniente de CODELCO.

Sewell es el único ejemplo de asentamiento minero industrial de montaña en Chile. Está situado en el Cerro Negro, cuya topografía y orientación son determinantes para la implantación de las edificaciones y el trazado de las vías peatonales, vehiculares y férrea. En la ladera norte se ubica la quebrada del río Coya, y al sur, la quebrada del río Teniente. Perpendicular a esta última se encuentra la quebrada del Diablo, que conforma una ladera de pendiente pronunciada y escarpada. La disposición de Sewell en el Cerro Negro fortalece su presencia como sello distintivo de la División El Teniente. Para el observador no parece haber edificios paralelos ni en ángulos rectos, lo que fragmenta, al ascender, los planos de las edificaciones, en un paisaje construido que refuerza la interioridad del espacio de la escalera central. Al descender, en cambio, se presentan planos de techumbres que parecen fugarse en el espacio geográfico. Las vistas cerradas y de perspectivas cortas dibujan el interior de la ciudad. El entorno se abre a las calles laterales en cuyo trasfondo los retazos de cordillera presentan la geografía, en dialéctica entre paisaje natural y paisaje construido.

La estructura urbana de Sewell está organizada a partir de la construcción de una gran escalera central por su espinazo. Sobre la ladera norte se localizan preferentemente los edificios habitacionales, y sobre la sur, los

Figura 3. Sewell: planta (Garcés, 2001).

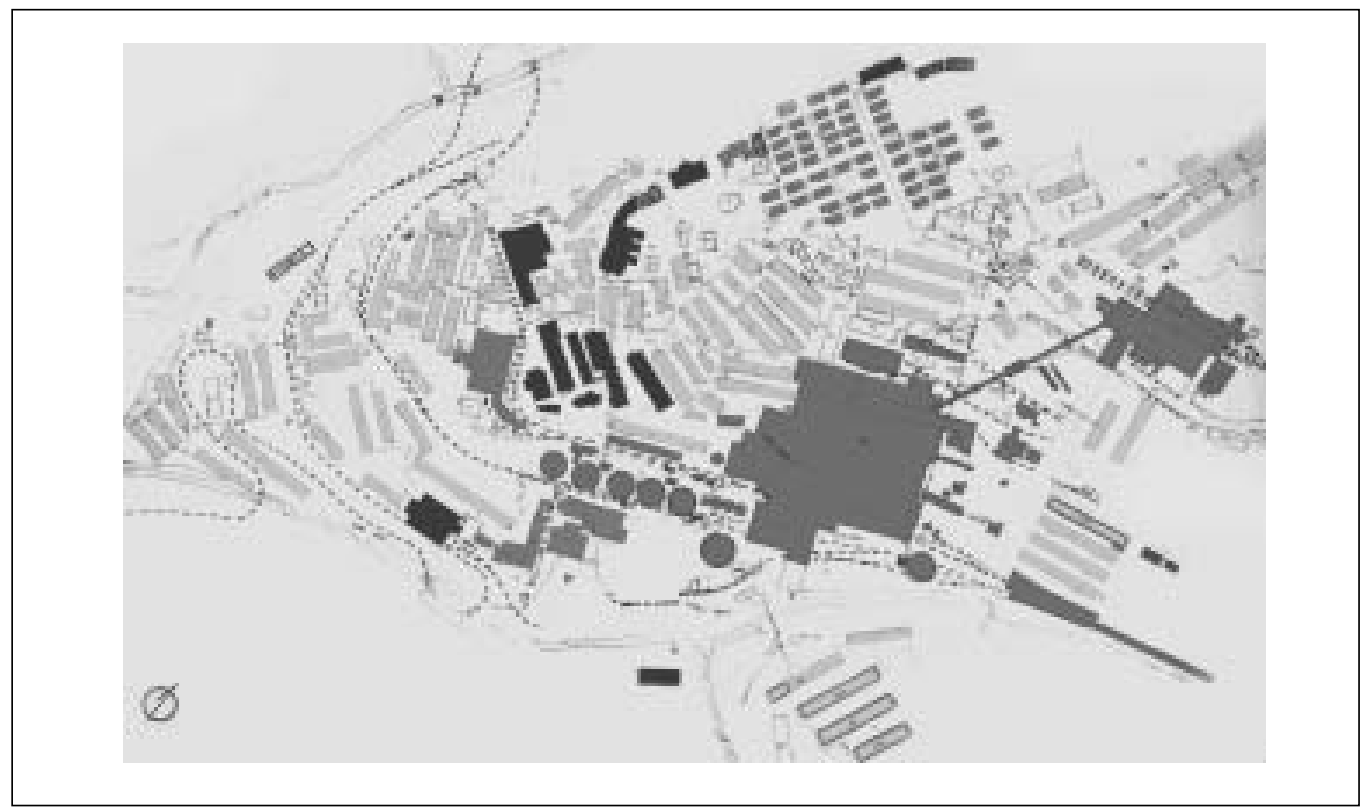


Figura 4. Sewell: foto aérea (Garcés, 2001).

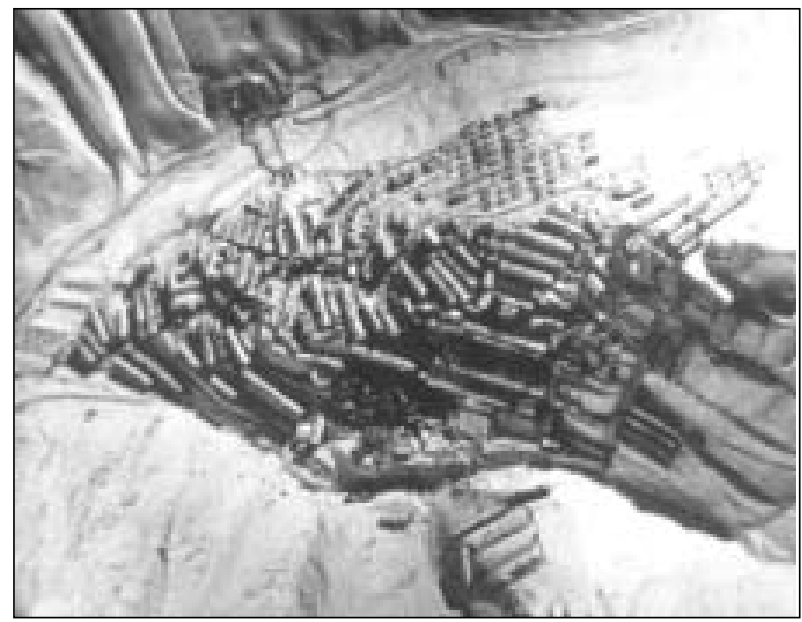

equipamientos e instalaciones industriales. De manera complementaria, en la Quebrada del Diablo fue construida la Población Sorensen, demolida en la década de los '70. La gran escalera central, se constituye en el espacio público de mayor importancia. Distribuye hacia los costados por ramales de circulación, a modo de espina de pescado, paralelos a las cotas, para permitir accesos a las viviendas, equipamientos e instalaciones industriales. Enlaza con pequeñas plazuelas que se abren a su paso, desde el hito topográfico Penstock y la plaza Morgan, en la base, la plaza del Teatro en el centro, la plaza del Patinaje en el límite del campamento y la plaza del Obrero del Cobre, en la base de la estructura ferroviaria llamada Punta de Rieles. Los vehículos motorizados tienen acceso a los bordes del sistema peatonal, en tanto que el ferrocarril se abre paso entre las edificaciones, pasando junto a la fundición, hasta aproximarse a la parte baja de la Planta de Concentración.

Los edificios de viviendas fueron construidos a partir de tres distintas tipologías: de circulación externa, con unidades habitacionales autónomas, similares a departamentos; de circulación central con corredor como elemento articulador lineal entre recintos; y de circula- ción perimetral que permite el acceso a dos crujías de cuartos, sin servicios. Por su parte, en el barrio americano se construyeron viviendas unifamiliares aisladas, actualmente demolidas, dispuestas escalonadamente en la fuerte pendiente, a partir de su organización en dos crujías paralelas a la cota.

Los edificios singulares se constituyen en hitos de referencia dentro del campamento. Un ejemplo es el Hospital, de planta compleja y volumetría destacada por su techumbre, de la que sobresalen las pequeñas ventanas del ático. En el costado sur del Cerro Negro se sitúa la Iglesia. Otro ejemplo de lenguaje moderno, es la Escuela Industrial, con tres niveles -además de piso zócalo y una singular fachada curva y escalonada, despojada de ornamento. Por último, el Club Social Teniente, de aspecto neoclásico, aún subsiste en lo que fue el barrio americano.

Entre las construcciones habitacionales destaca el edificio de vivienda colectiva 152, única edificación que se ubica contra la pendiente del cerro, con nueve plantas escalonadas, lo que le imprime una interesante presencia volumétrica. Entre las construcciones industriales destacan la estructura ferroviaria 
conocida como Punta de Rieles, ubicada en el punto más alto del campamento; el edificio de la Planta de Concentración, en la ladera sur del Cerro Negro, con sus cubiertas desplegándose en la pendiente; y el Puente Rebolledo, destinado al paso de la canoa de relaves.

La expresión arquitectónica resulta muy ajustada al tipo estructural, proceso constructivo y solución material: los sistemas en madera Balloon Frame y Platform Frame proporcionan el soporte a cubiertas de plancha de metal ondulado y paramentos de estucos sobre malla o plancha metálica, dispuestas directamente sobre la estructura.

A fines de la década del '60 Sewell inició un período prolongado de decadencia, relacionado con el traslado de sus habitantes a Rancagua a partir de la Operación Valle y la construcción de la Carretera del Cobre, en 1969 (Garcés, 1992). El total de la superficie demolida alcanza a las 18,8 há., equivalente a poco más de la mitad del área total, considerando zonas habitacionales e industriales. En este momento, la superficie total de Sewell es de $75.000 \mathrm{~m} 2$, de los cuales prácticamente la mitad corresponde a edificios habitacionales o de equipamiento, deshabitados y bajo condiciones de contaminación debido a la presencia de la fundición de Caletones, pocos kilómetros valle abajo. Es de destacar que en los últimos años, la División El Teniente ha realizado importantes avances en el control de emisiones.

A su vez, el campamento ha sido objeto de un plan de mantenimiento y puesta en valor, lo que ha permitido que Sewell haya sido declarado zona típica. Se estudia su habilitación como Museo Nacional de la Minería.

\subsection{Chuquicamata: el gran campamento minero (Chile Exploration Company, 1915)}

Chuquicamata está localizado a $1.600 \mathrm{~km}$. al norte de Santiago (Chile), entre los parale- los $22^{\circ}$ y $23^{\circ}, 16 \mathrm{~km}$. al norte de la ciudad de Calama, $135 \mathrm{~km}$ en línea recta de la costa y a 2.780 m.s.n.m. en la II Región, en medio del desierto de Atacama, caracterizado por sus condiciones extremas de temperatura, alta oscilación térmica, alta radiación solar, sequedad del ambiente, escasas lluvias y fuertes vientos dominantes. Forma actualmente parte de la División Chuquicamata de CODELCO.

El asentamiento fue diseñado a partir de un campamento obrero de gran precisión formal, en forma de rectángulo de $600 \mathrm{~m}$. por $800 \mathrm{~m}$. aproximadamente, definido por dos ejes perpendiculares: un par norte-sur (las avenidas E. Ramírez y Ch. Brinckerhoff) que lo conectaron con la ciudad de Calama, y otro, oriente-poniente (la avenida Tocopilla) paralelo a la línea férrea, que lo vinculó con las instalaciones industriales y el barrio americano. El campamento estaba constituido por una retícula ortogonal presidida por una explanada central. Las calles remataban perpendicularmente con los ejes principales, para generar una óptima conectividad entre cualquier punto dentro de su área y estos ejes, de modo de favorecer la disminución del tiempo de transporte entre residencia y lugar de trabajo. La trama ortogonal se impuso de manera categórica al terreno, recordando los asentamientos urbanos españoles en América, aun cuando la manzana -propia del arte del buen establecer hispano- se desdibuja en favor del uso del bloque de viviendas en hilera, dispuestas de a pares con pasaje en medio, tipología de origen anglosajón. La localización del campamento obrero, a unos 2.000 $\mathrm{m}$. del acceso al sector industrial, posibilitó la construcción de villas de viviendas, elementos de equipamiento y espacios públicos entre ambos polos, a lo largo de la avenida Tocopilla.

La explanada central en cuyo centro se situó la plaza mayor -que data aproximadamente de 1911- permitió la disposición de los edificios de servicios y equipamientos más representativos. La explanada, de $70 \mathrm{~m}$. por 170 m., tiene una doble lectura dimensional: por una parte, la medida acotada por los límites 
que definen los edificios de equipamiento ubicados en sus bordes, conteniendo el espacio de la explanada; y por otra, la medida de la plaza construida, de una sexta parte de la explanada. Estas dos escalas, la de la plaza y la explanada en que se sitúa, constituyen un factor determinante del espacio más característi$\mathrm{co}$, centro fundacional y principal lugar de referencia de Chuquicamata. El ambiente de fuerte sol, viento y oscilaciones térmicas obli- garon a favorecer el uso público intensivo interior de los edificios de equipamiento.

Entre el campamento obrero y el barrio americano, se construyó a lo largo de la avenida Tocopilla el hotel John Bradford y el Hospital Chuquicamata, a partir de un proyecto realizado por la oficina neoyorquina de York \& Sawyer. Fue inaugurado en el año 1962, con una capacidad de 250 camas.

Figura 5. Chuquicamata: planta (Garcés, 2001).

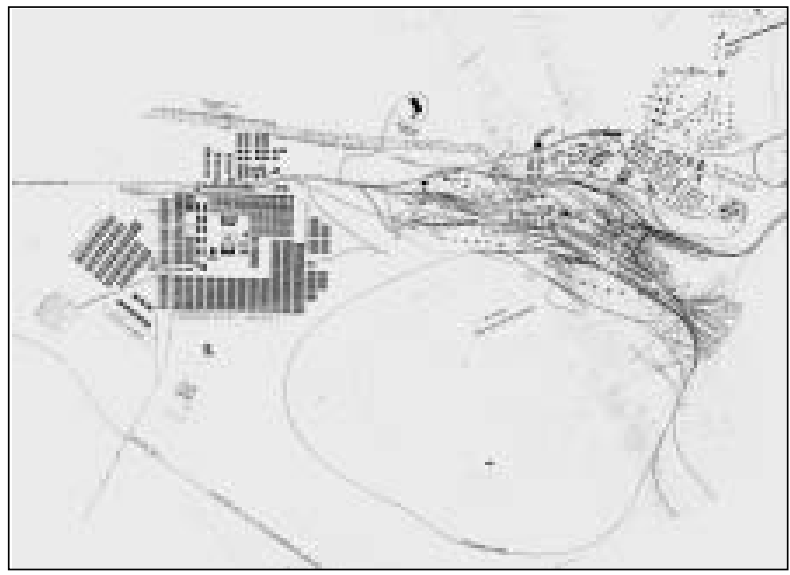

Figura 6. Chuquicamata: vista aérea (Garcés, 2001).

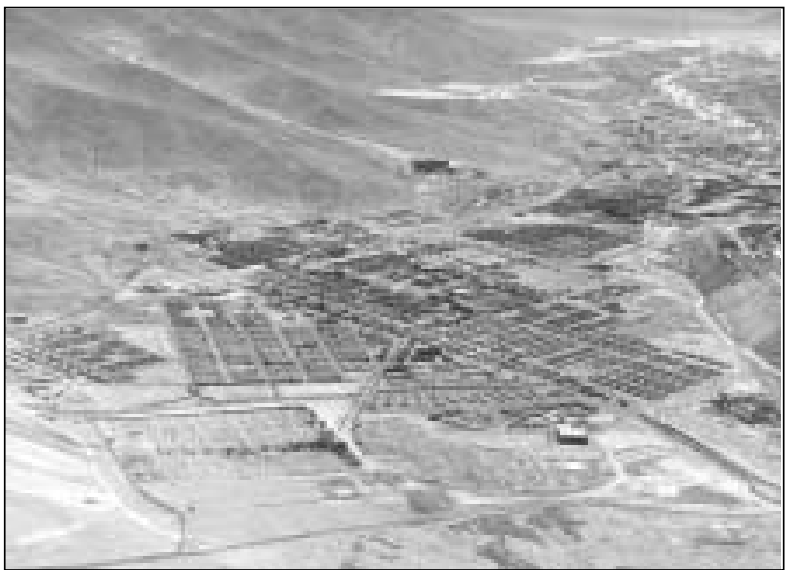


Al término de la avenida Tocopilla fue levantado originalmente el barrio americano, muy cercano a la mina. Estaba formado por viviendas aisladas que iban ascendiendo en pendiente hasta la denominada "Casa 2000", del gerente general, Daniel Guggenheim. Más abajo se disponían las viviendas de supervisores, todas ellas adaptadas a la topografía y a las condiciones climáticas extremas del lugar, con propuestas paisajísticas que incluían especies vegetales como pimientos, pinos, palmas chilenas, etc. Fue el barrio americano más grande de su tipo en la minería chilena. En la década de los ' 80 se desalojó debido al avance de las tortas de ripios sobre el área. Durante 1984, 150 viviendas para supervisores y profesionales fueron trasladadas al sur del campamento obrero, incluyendo la Casa 2000, formando un conjunto con el Club de Supervisores, otras casas de ejecutivos y la villa Auka Huasi.

En estos momentos, el campamento Chuquicamata está siendo desmantelado, de acuerdo con los lineamientos del Proyecto Traslado de todos los trabajadores y sus familias a la vecina ciudad de Calama.

\subsection{Potrerillos: del proyecto barroco al campamento minero (Andes Copper Mining Corporation, 1919)}

Potrerillos está localizado a $1.130 \mathrm{~km}$. al norte de Santiago (Chile), entre los paralelos $26^{\circ}$ y $27^{\circ}$, a $150 \mathrm{~km}$. del puerto de Chañaral y a 1.800 m.s.n.m. en la III Región, en la zona sur del desierto de Atacama. Forma actualmente parte de la División Salvador de CODELCO.

Potrerillos fue construido a partir de un primer proyecto (1919) basado en un trazado de sistema abierto -tipo barroco- con dos grandes ejes diagonales y uno central, proyectados desde una plaza principal situada en el cabezal jerárquico del proyecto. Los ejes diagonales se proyectaban en forma indefinida, sin considerar el territorio y su topografía. Complementario con los ejes, el trazado era ortogonal, con manzanas de forma rectangular y su lado mayor en contra de la pendiente, destinadas a las viviendas de los trabajadores, en contraste con el barrio americano, relativamente sinuoso, aprovechando las cotas del terreno. Los equipamientos fueron proyectados en torno de la plaza principal, vecina con el acceso al campamento situado en el punto más alto de la ciudad -la estación del ferrocarril-, con un completo dominio visual del campamento. Al eje de la plaza principal, en el centro del campamento, se previó la existencia de otras plazas, y al norte, un eje de espacios públicos que separarían el barrio americano del resto del campamento.

En el campamento construido entre 1920 y 1927, el trazado del proyecto original fue adaptado a la topografía. Se rellenaron algunas quebradas con ripios resultantes del proceso industrial, de manera de construir los bloques de vivienda de forma paralela a las cotas, con una disposición adecuada al asoleamiento, consiguiendo orientar las fachadas de los bloques en sentido oriente y poniente. El sector industrial fue situado al este del campamento, más arriba de las líneas del ferrocarril y la estación. Junto a ella se ubicaron el retén de carabineros, la escuela, la oficina del telégrafo y correos, la pulpería y el banco. La plaza, de 140 m. por 120 m., no pasó de ser un vacío urbano en pendiente, definido por algunos edificios de equipamiento. El resto del equipamiento se distribuyó por otros sectores del campamento: hacia el poniente de la plaza, el hotel, el edificio de sindicatos, el jardín infantil, el club Caupolicán, el teatro y el estadio, entre otros; hacia el sur, el estadio techado y el mercado público; y como parte del barrio americano, el hospital, el colegio, un club de golf y de tenis.

Dos tipologías de vivienda tuvieron mayor presencia: la pareada, que se encuentra principalmente en el barrio americano y en el sector norte alto, ambas presentes hasta hoy; y otra en hilera, que constituyó un tipo de edificación capaz de agrupar en forma flexible distintas organizaciones espaciales. Tras el 
terremoto de 1968 se construyeron nuevos barrios que reemplazaron las áreas inhabilitados por el sismo.

Hacia 1971 se construyó el nuevo acceso vehicular desde el sector poniente y a lo largo de la avenida Prat, complementario y luego sustituto del ferrocarril como forma de acceso al campamento. Este acceso permitió la implantación de nuevos equipamientos, constituyendo un centro lineal complementario de los edificios de equipamiento situados en torno a la plaza central.

Figura 7. Potrerillos: planta 1919 (Garcés, 2001).

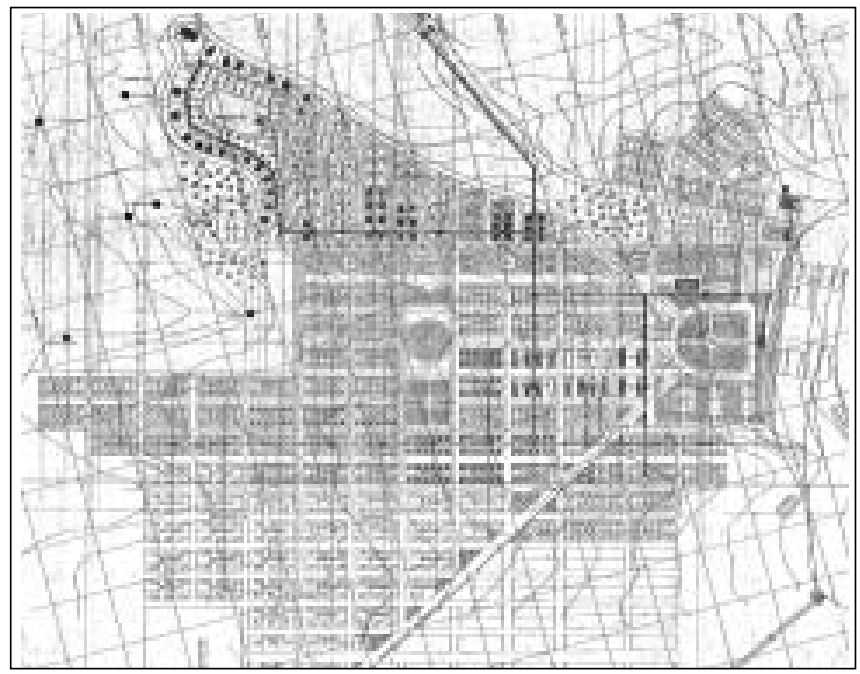

Figura 8. Potrerillos: planta 1990 (Garcés, 2001).

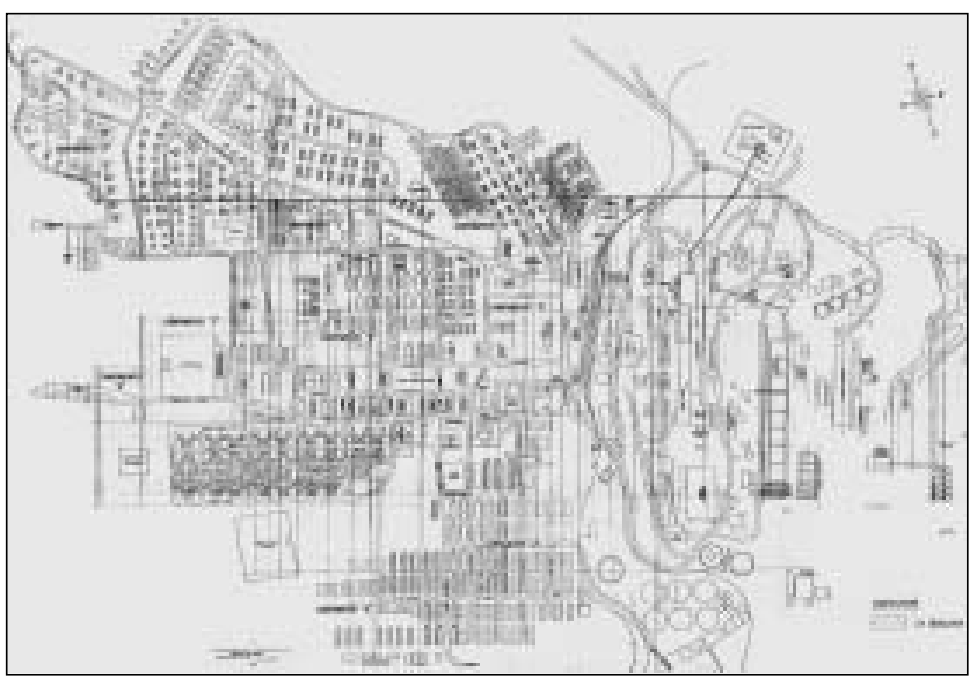


En 1997 se construyó una nueva plaza al centro del campamento, mediante terrazas y escaleras, cuando la decisión de cierre del campamento estaba prácticamente tomada, en atención a que fue declarado zona saturada de contaminación. En consecuencia, el campamento fue cerrado -no así la planta industrial- y la población trasladada a EI Salvador y otros lugares próximos como Diego de Almagro, Llanta y Copiapó.

\subsection{El Salvador: el campamento moderno (Andes Mining Copper Company, 1959)}

El Salvador se localiza a $1.100 \mathrm{~km}$. al norte de Santiago (Chile), entre los paralelos $26^{\circ}$ y $27^{\circ}, 32 \mathrm{~km}$. al norte de Potrerillos, a 2.300 m.s.n.m., $110 \mathrm{~km}$ de la costa y a $55 \mathrm{~km}$ al noreste de Diego de Almagro, en la III Región. Forma actualmente parte de la División Salvador de CODELCO.

El Salvador designa al nuevo yacimiento encontrado en 1954 a $2.400 \mathrm{~m}$. de altura, al oeste de la sierra del Indio Muerto, y en particular, al lugar planificado para la función habitacional. El campamento fue proyectado considerando la construcción de 1.200 viviendas para alojar a 6.500 personas, lo que da un promedio algo superior a cinco personas por vivienda, densidad adecuada para un campamento modelo, incluyendo disposiciones de carácter social para sus trabajadores al alero del New Deal, propuesto para Latinoamérica por Estados Unidos, que incorpora conceptos de calidad de vida descrita en términos de good living, health and recreation. La memoria de proyecto del arquitecto Olson (1958) es clara en este sentido, recordando las propuestas del Team 10 y las primeras New Towns:

"1. El diseño curvo fue realizado para evitar la monotonía desplegada en muchos campamentos organizados con una estricta retícula de damero.

2. El campamento fue situado en un anfiteatro natural. El terreno se eleva gradualmente desde el punto focal del se- micírculo hacia los bordes del campamento, en un ascenso gradual aproximado de $27 \mathrm{~m}$., en una distancia de $600 \mathrm{~m}$.

3. El Salvador es una 'comunidad peatonal' en la cual los equipamientos como centro comercial, lugares de reunión, oficinas públicas e iglesia cerca de la plaza, se encuentran a una distancia fácil de caminar desde todas las viviendas.

4. Las áreas de recreación y equipamientos están localizados en áreas apropiadas por su cercanía con los vecindarios y distribuidas de manera uniforme.

5. El transporte de empleados y obreros a la mina se realiza de la manera más conveniente posible para todos los usuarios. Son apreciables los numerosos paraderos de buses en el arco semicircular, situado en el centro.

6. Con propósitos de seguridad para los niños pequeños, las escuelas fueron dispuestas lejos de las áreas de tráfico, de manera que los niños pueden ir hacia y desde el colegio por áreas de menor flujo de tráfico, en la periferia del campamento.

7. El hospital está situado a mano de todas las áreas residenciales.

8. Se han usado 10 diferentes colores pastel, compatibles entre sí, para decorar las viviendas, de modo de evitar toda apariencia de monotonía.

9. También se ha evitado la monotonía variando el diseño de las viviendas unifamiliares. Fueron diseñados cuatro tipos de viviendas, cada uno con diferentes modelos de tres y cuatro habitaciones.

10. La combinación de colores pastel en los muros con techos de un blanco brillante (para reflejar el calor) pretende otorgar a EI Salvador una apariencia semejante a las casas blancas y rosadas de techo blanco que exhiben las viviendas de Las Bermudas. La apariencia de El Salvador va a estar realzada por el hecho que las viviendas se dispondrán en una serie gradual de crecientes semicírculos, desde la plaza hasta los bordes del campamento". 
El Salvador fue proyectado con precisión formal y funcional, a partir de un trazado geométrico de anillos concéntricos siguiendo la forma de un anfiteatro, que recuerda al casco minero, y un programa de "ingeniería social" especificado en detalle. El proyecto planteaba un orden geométrico de semicírculos concéntricos de $180^{\circ}$ desde la plaza como foco de la composición. Sobre el semicírculo central convergen un par de avenidas diametrales y sendas avenidas perpendiculares a las anteriores, que rematarían en el extremo superior del campamento, donde se proyectó el equipamiento deportivo.

Estos pares de ejes se complementaban con los dos pares de avenidas a 45으, que alcanzan el semicírculo, y cuatro pares de avenidas complementarias, dando lugar a los triángulos destinados a espacios públicos y edificios de equipamientos. Hacia el oeste el proyecto se prolonga para dar origen al barrio americano. Entre estas dos formas urbanas, bien definidas, aparece un amplio espacio central, de grandes manzanas libres, adyacente al sur de la plaza y que separa ambos sectores residenciales. Finalmente, un semicírculo más pequeño, dispuesto en el extremo suroriente de la composición, cierra el conjunto de avenidas semicirculares, equilibrando la geometría del proyecto. El equipamiento dispuesto en el centro, en torno a la plaza, corresponde a las oficinas públicas, bancos, restaurantes y área comercial. Los servicios de carabineros, bomberos y el hospital fueron proyectados en el espacio central. Los colegios y las canchas de tenis y de fútbol estaban situadas en los extremos del campamento y en el barrio americano. Los triángulos resultantes de las intersecciones de las avenidas radiales con las semicirculares se destinaron a espacios públicos con paraderos de buses. Para potenciar el carácter peatonal del campamento se crearon otras plazas dispuestas a lo largo de la avenida principal y en el barrio americano.

En diciembre de 1966 ya eran apreciables los cambios respecto del proyecto original. El campamento había crecido hasta 12.000 habitantes, hecho que hizo aumentar el programa de equipamientos y de viviendas en base a soluciones que en parte han desdibujado el proyecto original y su trazado concéntrico ajustado y preciso. Se han obviado parcialmente sus leyes básicas, presionadas por el crecimiento del campamento, la existencia de un obstáculo topográfico como la quebrada que el proyecto no consideró, el establecimiento de nuevas edificaciones, cambios en los usos urbanos de avenidas y accesos, desarrollo in-

Figura 9. El Salvador: planta de R. Olson (Garcés, 2001).

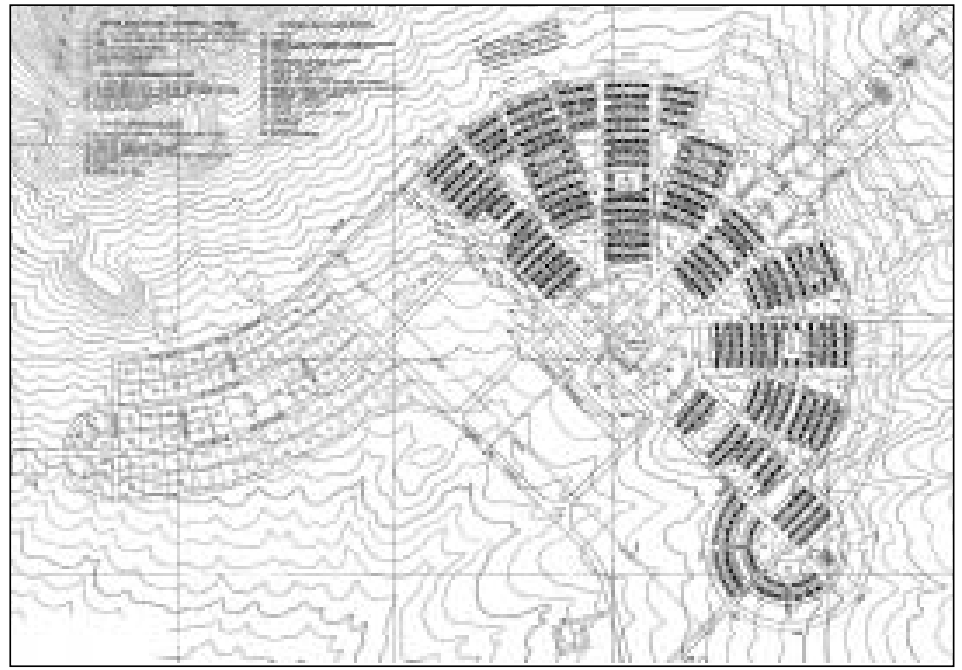


formal del gran espacio vacío central cuya ocupación no previó el proyecto original, ampliaciones y transformaciones de las viviendas (Ortúzar et al., 2000).

\subsection{San Lorenzo: la villa minera (Compañía Minera Escondida Limitada, 1995)}

La villa minera San Lorenzo, de Minera Escondida, está localizada a $1.550 \mathrm{~km}$. al norte de Santiago (Chile), aproximadamente en el paralelo 24을 a $220 \mathrm{~km}$. de la ciudad de Antofagasta y a 3.150 m.s.n.m., en la II Región. Forma parte de la Compañía Minera Escondida Limitada.

La Villa San Lorenzo es la materialización física de una política que enfrentó con una perspectiva distinta el tema de las construcciones de habitación y servicios para su personal, como resultado de un esfuerzo conjunto entre profesionales de la propia compañía minera, la oficina de arquitectura Pfenninger y Sologuren y la empresa constructora. La noción de campamento, tradicional en el ambiente minero, fue sustituida por el de villa, intentando caracterizar nuevas relaciones laborales que fuesen capaces de reemplazar con eficacia a los campamentos de CODELCO, asumiendo toda la experiencia acumulada por
80 años de asentamientos mineros del cobre. Desde el punto de vista habitacional, la compañía estableció dos focos: en el área de operaciones desarrolló tres campamentos para el personal en faenas, y para los trabajadores y sus familias construyó conjuntos de viviendas en Antofagasta.

Los campamentos corresponden al campamento mina, con capacidad para 1.000 personas; el Campamento 2000, para contratistas, con capacidad para 2.000 personas; $y$ la villa San Lorenzo, para 2.000 personas. Estos dos últimos se localizan a unos cinco kilómetros de la mina.

La Villa San Lorenzo corresponde, de acuerdo con las definiciones de las nuevas empresas mineras, al campamento de operación, que consiste en instalaciones construidas para albergar al personal que opera la mina durante el proceso de explotación minera e industrial. Es un conjunto de tres manzanas de dormitorios y servicios, de $50 \mathrm{~m}$. por $50 \mathrm{~m}$. por lado, con un patio interior de 26 m. por 26 $\mathrm{m}$., dispuestos a uno y otro lado de un bloque central alargado que contiene los distintos equipamientos y servicios. Al interior de cada manzana hay un edificio aislado con programa comunitario, salas de juego, estar y baños. Las manzanas están formadas por dos

Figura 10. El Salvador: planta actual (Garcés, 2001).

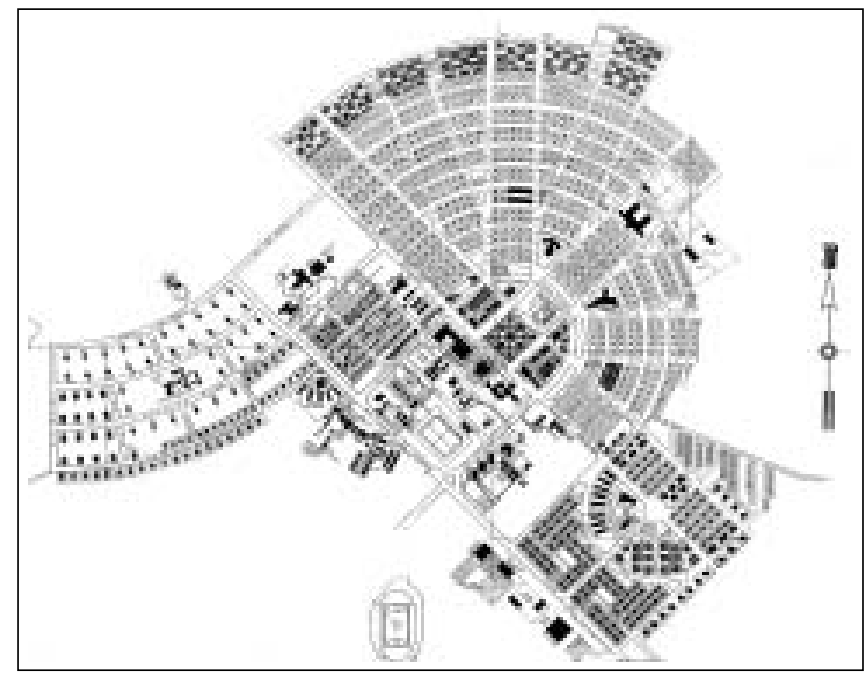


Figura 11. Villa San Lorenzo: planta (Garcés, 2001).

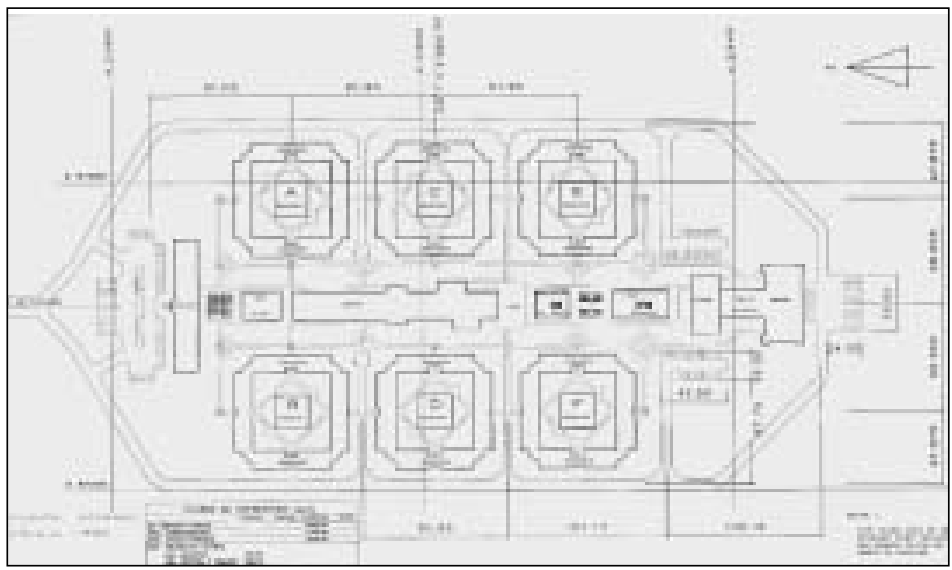

Figura 12. Villa San Lorenzo: maqueta (Garcés, 2001).

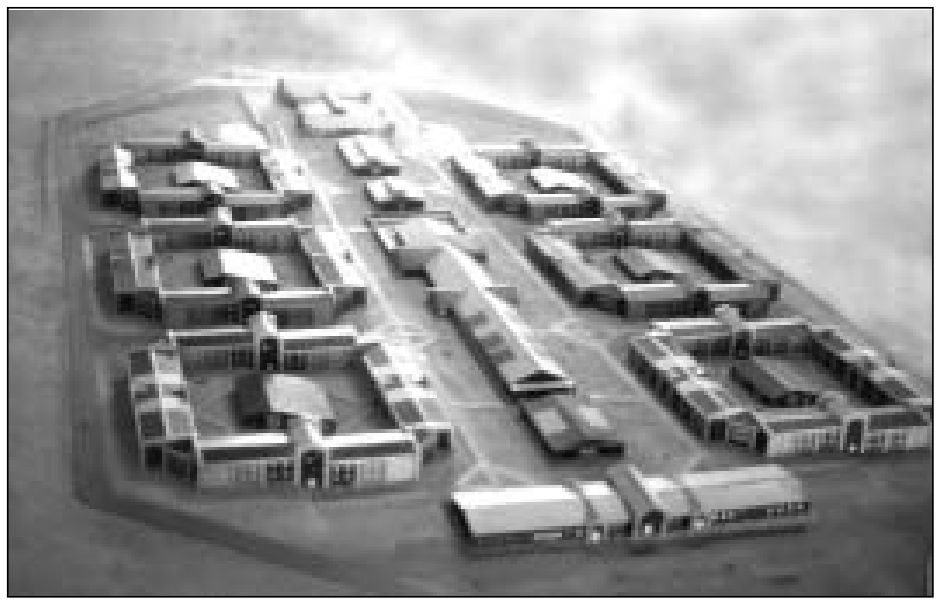

crujías de dormitorios y baños, a uno y otro lado de un largo pasillo. Las esquinas se formalizan mediante la continuidad del pasillo. Junto a los accesos, caracterizados por un tímpano triangular, se sitúan las escaleras y el ingreso al patio interior.

El bloque central está constituido por los principales recintos de equipamiento, formando la columna vertebral del conjunto, con servicios independientes, utilizables en horarios diferentes y accesos diferenciados: casino, gimnasio, piscina, capilla católica y evangélica y oficinas generales. Este bloque central se encuentra flanqueado por espacios longitudinales, a la manera de avenidas pea- tonales descubiertas, que permiten la circulación hacia los núcleos de dormitorios a la vez que el tránsito entre ellos y el eje central.

El programa de la villa fue estudiado en relación con un sistema de turnos rotativos de 4 por 4 días, divididos en cuatro grupos. Cada turno corresponde a cuatro días de trabajo, alojando en el campamento y cuatro días de descanso, en la ciudad de Antofagasta.

Este sistema de turnos permite que siempre coexistan dos grupos en la villa: uno en el turno de día y otro en el de noche, por lo que la intensidad de uso de los espacios comunes es escasa, tanto de las manzanas como del 
bloque central, considerando un máximo de cuatro horas disponibles para la utilización de los espacios recreativos y de servicio.

\subsection{Portal del Inca: el hotel minero (Compañía Minera Doña Inés de Collahuasi, 1999)}

El Hotel Minero Portal del Inca está localizado a más de $2.000 \mathrm{~km}$. al norte de Santiago (Chile), poco al norte del paralelo 21으, a 185 $\mathrm{km}$. al sureste de la ciudad de lquique, a una altura de 3.850 m.s.n.m., en la I Región. Forma parte de la Compañía Minera Doña Inés de Collahuasi.

La compañía minera fue organizada en función de tres focos de operación. El primero de ellos es el complejo minero y residencial Portal del Inca, situado en el área del Salar de Ujina, al que se accede desde lquique por un camino pavimentado de $185 \mathrm{~km}$. y un aeródromo. Lo conforman los yacimientos cupríferos de Ujina, Rosario y Huinquintipa, donde se realizan operaciones de extracción y procesamiento del mineral. El segundo foco es el puerto de Punta Patache, $70 \mathrm{~km}$. al sur de lquique, donde se embarca la producción de concentrado de cobre, transportada desde la mina mediante un mineroducto de $200 \mathrm{~km}$. de extensión. El tercero lo constituye la ciudad de lquique, donde se construyeron el condominio La Tirana y el condominio La Portada.

La compañía minera y los arquitectos Correa 3 propusieron un cambio radical en el concepto y tipología de campamento, considerando los nuevos conceptos ya introducidos por Minera Escondida. Había que adoptar nuevos estándares en la disposición de funciones y espacios, para generar un ambiente que pudiese aminorar al máximo la falta de confort físico y psíquico, producto de las condiciones ambientales desérticas de altura, y promover el compartir con los demás trabajadores y empleados e interactuar con el medio circundante de manera positiva. Para ello se pro- yectó una nueva tipología residencial, distinta del campamento y de la villa, más ajustada a las nuevas modalidades de relaciones laborales y mayor eficiencia en el uso del tiempo laboral y recreativo. El nuevo concepto fue el de hotel minero, que evoca ideas asociadas con lo temporal y lo provisorio -relacionado con el sistema de turnos- y sugiere estándares de calidad vinculados con la hotelería.

Desde un punto de vista constructivo se adoptó un criterio semejante al utilizado por Minera Escondida, es decir el de módulos prefabricados, en este caso de 3.60 m. por 13.30 $\mathrm{m}$., transportados en camiones desde Santiago hasta la obra. A diferencia con la villa San Lorenzo, los módulos se dispusieron en forma perpendicular al plano de fachada, en tres pisos de altura.

El Hotel Portal de Inca ofrece todo lo necesario para la vida del personal en faena, su alimentación, descanso y distracción, incorporando vegetación a los interiores, en contraste con el paisaje exterior de desierto, montañas y salares. Los dormitorios se dispusieron en pabellones longitudinales que permiten a los trabajadores el recorrido por el edificio para llegar al comedor. En ese recorrido cruzan los jardines interiores, situados en un espacio de triple altura con iluminación cenital, y los espacios de esparcimiento, en un ambiente climatizado que permite el encuentro de las personas.

El conjunto presenta una estructuración cruciforme, con un edificio de tres alas destinadas a habitación y una cuarta, separada de las anteriores, que comprende los principales servicios del conjunto. La separación permite generar entre los dos cuerpos el acceso al conjunto, controlado visualmente, que da la idea de abrigo frente a la vastedad característica del paisaje. El punto central y de mayor uso dentro del conjunto lo constituye el espacio de ingreso hacia los edificios principales de dormitorios y de servicios. 
Eugenio Garcés

Figura 13. Hotel Portal del Inca: planta (Garcés, 2001).

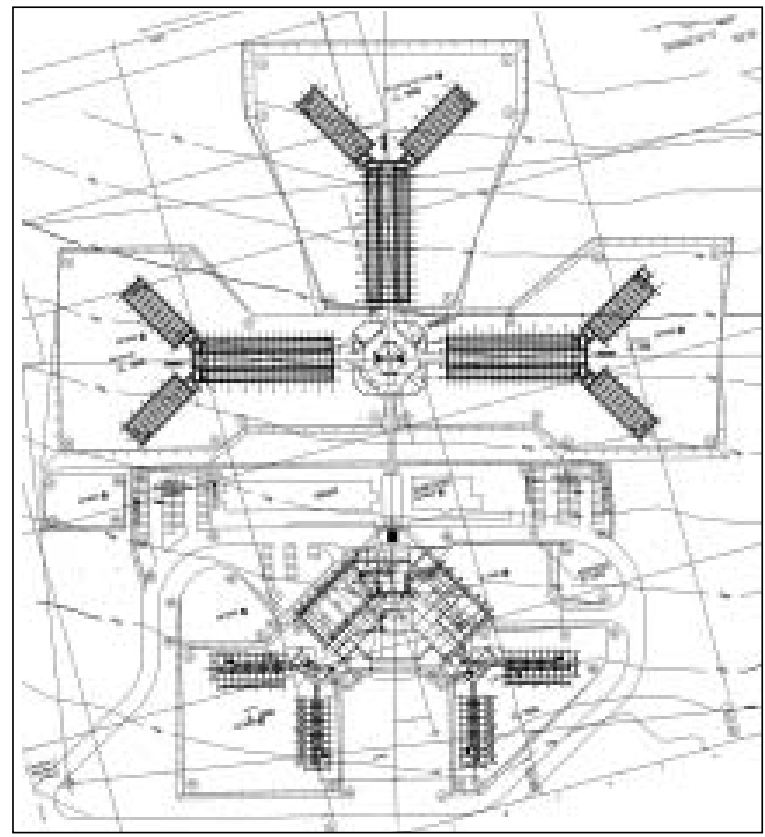

Figura 14. Hotel Portal del Inca: vista aérea (Garcés, 2001).

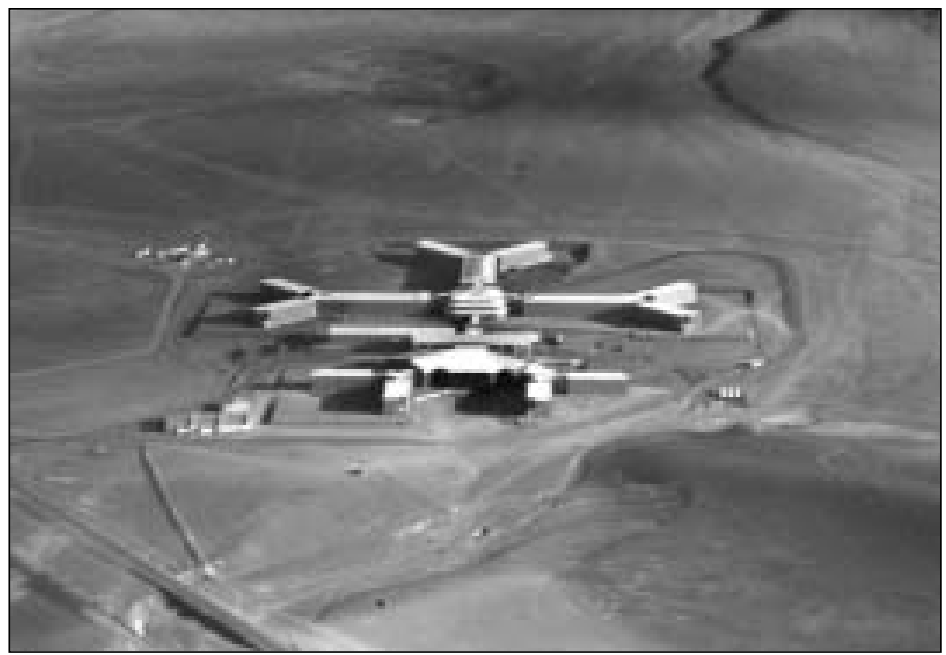

\section{Las ciudades del cobre como formas excepcionales del hecho urbano}

Un problema teórico que se presenta a la vista de los casos que se estudian es la capacidad de constituir ciudad que han tenido estas ciudades del cobre. Porque si compare- cen como asentamiento minero, campamento minero, villa minera y hotel minero, ¿bajo qué concepto los inscribimos? Un ejemplo es Chuquicamata, el caso más grande en tamaño, número de habitantes y complejidad de los que se presentan en este artículo, y que sin embargo se encuentra en proceso de desmantelamiento, por lo que no cumple con 
uno de los atributos de la ciudad, cual es su permanencia en el tiempo.

Le Corbusier (1957), en el contexto del Cuarto Congreso Internacional de Arquitectura Moderna (CIAM), reconoce cuatro funciones esenciales asociadas al habitar colectivo del hombre, presentes en todo proyecto de establecimiento humano: trabajo, esparcimiento, circulación y residencia. Aymonino (1972) plantea que "la ciudad es la representación de la sociedad en el espacio", aproximación que pone de relieve la idea de ciudad como institución, un lugar dotado de una carga simbólica, un escenario del poder como lugar con significados compartidos. Sjoberg (Morris, 1984) define la ciudad como "una comunidad de considerable magnitud y elevada densidad de población que alberga en su seno a una gran variedad de individuos especializados en tareas no agrícolas, incluyendo entre éstos a una elite culta". Munizaga (1997) define la ciudad como un asentamiento, relativamente grande y permanente, de población heterogénea, con funciones diversas y autarquía y territorio propio. De este modo, el hecho urbano está caracterizado por aspectos funcionales, su condición simbólica en la que se representa la sociedad, el aspecto material y formal de la ciudad, su vitalidad compleja e intensa y -desde luegosu permanencia en el tiempo.

En nuestro caso, la idea de asentamiento parece la más adecuada para definir el conjunto complejo de funciones y edificaciones de viviendas, equipamientos e instalaciones industriales, organizadas por sistemas de trazado que le permiten su organización interna, al mismo tiempo que su articulación con el resto de los elementos y centros poblados del territorio. El concepto de campamento estaría asociado a una forma menor en sus dimensiones físicas, ambiciones temporales y complejidad funcional, que incluye las funciones y construcciones relacionadas con la residencia y su ubicación a modo de satélite de una ciudad mayor (Sargent, 1990).
El interés de los casos que se han presentado radica en que, en tanto asentamientos industriales y en particular mineros, son manifestaciones de un modo de hacer ciudad derivada de la company town, vinculado con la ocupación productiva de territorios complementarios. Esta ocupación productiva se realiza a partir de tipologías edilicias y morfologías urbanas que han ido evolucionando a lo largo del siglo XX, desde ejemplos surgidos en el ámbito de la Revolución Industrial hacia nuevos modelos, relacionados con el contexto productivo, geográfico, espacial e histórico en que se sitúan. Son paradigmas para la comprensión del problema más genérico de un modo de habitar segregado respecto de la sociedad y las ciudades tradicionales, relacionados con actividades extractivas y productivas, dependientes de una administración empresarial centralizada. Los ha habido con poblaciones que superan los 20.000 habitantes en momentos de su mayor apogeo, han tenido una fuerte identidad y complejidad urbana, fueron construidos con tecnologías de avanzada, formaron parte de un sistema con amplias repercusiones en los territorios y han carecido de permanencia en el tiempo.

La noción de asentamiento minero permite caracterizar algunos casos, como Chuquicamata y Potrerillos, por la fuerte relación entre campamento e industria. El Salvador, al no estar relacionado con un área industrial, se asocia con la idea de new town minera. Los tres casos adoptaron una forma urbana caracterizada por su trazado, zonas residenciales y equipamientos; tienen o tuvieron una plaza central como espacio público jerárquico; tienen o han tenido procesos de crecimiento, normalmente administrados por la empresa; permiten o han permitido un intercambio social en cierta forma semejante al de una ciudad tradicional, aunque con aspectos restringidos. El campamento de montaña es una variante de la categoría anterior, con una fuerte componente geográfica que determina su organización, haciéndola singular, como es el caso de Sewell. 
Villa San Lorenzo y Hotel Portal del Inca, los ejemplos de construcción más reciente, se caracterizan por tener edificaciones unitarias y homogéneas que conforman un complejo mayor. San Lorenzo permite hacer de puente entre la idea de campamento y de hotel. El hotel minero marca una clara ruptura respecto de los casos tradicionales, pudiendo leerse como una máquina de habitar que recuerda paradigmas modernos.

De este modo, las empresas mineras privadas propusieron, a fines del siglo $X X$, una estrategia que supone una polarización y desagregación del modelo, a partir del progreso en los sistemas de comunicación en todos sus niveles: mejores vías de comunicación, nuevos sistemas de transporte de carga y pasajeros -al tren se agrega el autobús y el camión y finalmente los ductos mineros- y el avance de las telecomunicaciones; el manejo de los aspectos ambientales, que empiezan a regular cada vez más las condiciones de vida de los distintos asentamientos humanos, críticos en los asentamientos mineros chilenos, con altos índices de contaminación generados por la industria, hecho que ha obligado a introducir una distancia mayor entre las actividades industriales con la residencia; la superación del esquema de company town que obligaba a la prestación de servicios para sus habitantes -trabajadores y familias.

La separación de funciones implica un descargo en los gastos generados por estos servicios, entregados por ciudades próximas, funcionales a los intereses industriales, las que asumen o a lo menos comparten gran parte de estos costos. La noción de industria -company- es relacionada con las instalaciones industriales y obras de infraestructura vinculadas con la extracción, procesamiento, transporte y embarque del producto. La idea de pueblo o poblado -town- toma dos direcciones: una, la villa u hotel para el alojamiento, relacionado, pero a una cierta distancia, de la industria, en sistema de turnos; y dos, condominios para las familias de los mineros -obre- ros, empleados, técnicos, ejecutivos-en una ciudad vecina.

A fines del siglo $X X$, la villa minera y el hotel minero han terminado reemplazando a la ciudad minera.

\section{Referencias bibliográficas}

Aymonino, C. (1972). Orígenes y desarrollo de la ciudad moderna. Barcelona: Gustavo Gili.

Dal Co, F. (1975). "De los parques a la región". Ciucci, G. et al., La ciudad americana de la Guerra Civil al New Deal. Barcelona: Gustavo Gili.

Garcés, E. (1999). Las ciudades del salitre. Santiago: Orígenes.

Garcés, E. et al. (1992). "Sewell asentamiento minero (1904 hasta la actualidad)". Arquitectura Panamericana, 001: 104-117. (2001). "Los campamentos de la minería del cobre en Chile (19052000)". Informe final Proyecto Fondecyt 1990485.

Le Corbusier (1957). La Charte d'Athènes. Paris: Points Essais.

Olson, R. (1958). "Memoria proyecto El Salvador". Engineering and Mining Journal, 159, 11.

Ortúzar, P. et al. (2000). "Las viviendas de El Salvador". Taller de Investigación Asentamientos mineros del cobre en Chile, $2^{\circ}$ semestre 2000. Santiago: Escuela de Arquitectura, PUC.

Morris, A. E. J. (1984). Historia de la forma urbana. Desde sus orígenes hasta la $R e$ volución Industrial. Barcelona: Gustavo Gili.

Munizaga, G. (1997). Diseño urbano, teoría y método. Santiago: Ediciones Universidad Católica.

Reps, J. W. (1965). The making of Urban America. A history of city planning in the United States. Princeton, New Jersey: Princeton University Press.

Sargent, L. (1990). "Campamento de Exploración”. Revista $A R Q, 15$. 